\title{
A Design SCIENCE APPROACH TO DEVELOP A NEW COMPREHENSIVE SOA GOVERNANCE FRAMEWORK
}

\author{
Fazilat Hojaji $1^{1}$ and Mohammad Reza Ayatollahzadeh Shirazi ${ }^{2}$ \\ ${ }^{1}$ Amirkabir University of Technology, Computer Engineering \& IT Department \\ Information \& Communication Technology Department of Isfahan Municipality \\ hojajidaut.ac.ir \\ ${ }^{2}$ Member of academic board Amirkabir University of Technology, \\ Computer Engineering \& IT Department \\ Hafez ST,Tehran, Iran \\ ashirazi@dpco.net
}

\begin{abstract}
SOA governance has a critical role in achieving success and realizing the benefits of SOA. Without effective SOA governance, organizations will experience some significant challenges including difficulties in designing effective decision structures and managing services. To address SOA challenges, organizations require a comprehensive SOA governance framework to implement management and control mechanisms. Study of existing frameworks reveals that these frameworks are not expressive enough to cover all elements of SOA governance and also, they do not completely document underpinning structures such as processes, procedures, responsibilities and measurement metrics. In this paper, we propose a new SOA governance framework that is more comprehensive and expressive than its counterparts. In the process of developing the framework, a set of important elements for a desired SOA governance framework is proposed. Based on these elements, a new SOA governance framework is developed. The proposed framework is obtained by extending characteristics of COBIT and applying ITIL service lifecycle activities to support the SOA governance principles and requirements. It is a perceptible framework that clarifies all processes, activities, metrics and other related elements in a logical structure. Also, to simplify the application of the framework, an implementation process is proposed.
\end{abstract}

\section{KEYWORDS}

SOA governance, service lifecycle, SOA roadmap, SOA adoption, COBIT

\section{INTRODUCTION}

SOA is an architectural approach for building applications by using a set of loosely coupled reusable, standards-based, and well-defined services [1]. However, most organizations face significant challenges and obstacles in their SOA implementation. The main challenges of SOA implementation are difficulties in designing effective decision structures, building a SOA roadmap, managing and governing services, identifying services and also lack of service funding and lack of consistent governance processes $[2,3]$. To address these challenges, organizations require a comprehensive SOA governance framework that can be deployed in an iterative manner. A SOA governance framework defines an incremental deployment approach to meet the organization demands that increases effectiveness and efficiency in implementing, operating, and 
International Journal of Managing Information Technology (IJMIT) Vol.4, No.3, August 2012

managing SOA as well as providing value to the business. A number of SOA governance frameworks have been proposed by researchers and practitioners. The scope and coverage of these frameworks differ extensively. However, they have not completely documented SOA processes and activities, governance procedures and SOA roadmap, and they have some shortcomings to cover important elements of SOA governance such as service portfolio management, performance metrics and policy enforcement. The aim of this paper is to propose a more comprehensive framework hoping to remedy these widespread shortcomings. This framework offers a well-defined, structured set of aspects that an SOA governance framework should include. In this research, in the process of proposing a new SOA governance framework, a set of necessary elements for solving governance problems in a SOA implementation have been proposed. On the basis of these elements, some well-known SOA governance frameworks have been compared and their strength and weaknesses have been determined. The comparison results provide the groundwork for designing a new SOA governance framework. The suggested framework, although based on COBIT framework [4], extends and modifies it to address the unique requirements of SOA governance. In the proposed framework all imperative elements of SOA governance especially service lifecycle processes, performance metrics and SOA maturity that the existing frameworks do not completely covered them - can be entirely supported. The framework can be used for various evaluation techniques:

- Feature analysis - The evaluation is done by referring to the available resources.

- Case studies - The evaluation is done by examining the results of case studies.

- Field experiments - The evaluation is done by examining the results of field experiments.

Due to lack of space we will not discuss the advantages and drawbacks of each technique. However, such a discussion can be found in [5]. In this paper, we perform the evaluation using the feature analysis technique to demonstrate its applicability and ease of use. An evaluation of this type can be easily performed by an organization, because it can be performed internally within the organization. Also a qualitative evaluation is done based on criteria such as expressiveness, applicability and etc. Further evaluations can be possible by practitioners when the framework is published in public domain.

The rest of the paper is structured as follows: The applied design research methodology is introduced in section 2. In section 3, an overview of the problems and challenges which SOA governance should solve are presented and also, a set of important elements for SOA governance is proposed. In section 4, the new SOA governance framework is introduced and its main components are briefly described. We demonstrate our framework in section 5 by applying the framework in an IT department as a case study, which is the first part of the evaluation. In section 6 , we evaluate further and discuss our approach by evaluating the fitness of SOA governance elements and also, examining with a qualitative model. Finally, the last section closes with a brief summary and an outlook to further research.

\section{RESEARCH APPROACH: Applying a design science research methodology}

For the development of a new SOA governance framework, we have applied the problemcentered approach of the design science research methodology (DSRM) presented by Peffers et al. [6] while aligning the seven guidelines of design science defined by Hevner et al. [7]. We selected a design science approach for our research methodology since it addresses important 
International Journal of Managing Information Technology (IJMIT) Vol.4, No.3, August 2012

unsolved problems in a unique or innovative way or solved problems in a more effective way. The DSRM approach consists of six main activities which we present with each chapter of this paper in detail. From a top level methodological perspective we utilize different research techniques in each step and perform some activities to appropriately support our overall objective. The activities we have followed in this research are as follows:

Problem Identification: We specify the targeted domain (e.g. SOA and SOA governance), and justify the value of a solution. Based on the problem scope, we identify the main requirements, challenges and implications of SOA adoption and propose a set of SOA governance elements.

Define the Objectives of a new Solution: We analyze some of the existing SOA governance framework by means of a literature review to find their weaknesses and strengths. This analysis specifies a design strategy for developing a new SOA governance framework.

Design and Development: We design a new framework and present a generic conceptual model and a process model to articulate the distinctive features and core components of the proposed framework.

Demonstration: For demonstration of the designed framework, we apply the new framework in an IT department. Also, we construct a detailed implementation process around our framework to demonstrate its utility.

Evaluation: To evaluate the framework, we use common techniques of evaluation in design science research [7].We examine the framework by looking at its capabilities and evaluating the fitness of SOA governance elements. Also, it is analyzed with a qualitative model.

The two first activities of the research approach have been thoroughly reported in [8]. However, we present the important obtained results of these activities in section 3 to have more clarity in the design process. By using the results of these steps, a new SOA governance framework has been developed. The proposed framework has different components and various concepts. The introduction of the framework and two main components of the framework have been briefly reported in [9]. The current paper provides a description of the proposed framework and all of its core components and also a complete picture of the framework including the structure of the framework and the knowledge and concepts encapsulated within the framework. Furthermore, the two last step of the research approach (demonstration and evaluation) will be entirely presented. Several appendices are also provided as useful references for deploying the framework in organizations.

\section{Problem DEFINITION: SOA governance challenges and design strategy for new SOA governance framework}

As more and more companies move toward implementing service oriented architecture, they have to apply decision structures and control mechanisms for achieving success and realizing the benefits of SOA. In transition to SOA, companies face a series of challenges such as difficulties in designing an effective decision structure, managing and governing services and lack of consistent governance processes [3]. Therefore, to address these challenges and achieve SOA benefits, organizations require deployment of an appropriately detailed SOA governance model that can be deployed in an iterative and incremental manner. According to the research approach, 
International Journal of Managing Information Technology (IJMIT) Vol.4, No.3, August 2012

the initial step is to understand targeted domain (e.g. SOA and SOA governance), and identify the main requirements, challenges and implications of SOA adoption. A summary of several commonly occurring problems and challenges in SOA adoption with a complete list of capabilities needed to address these challenges have been presented in Table1. The left column describes the challenges and problems. The required capabilities to address and resolve each problem is presented in the middle column of Table 1. The list of SOA governance elements has been shown in the third column of Table 1. These elements provide a foundation to analyze existing SOA governance frameworks and develop a more comprehensive framework.

Table1. SOA challenges and related SOA governance elements [8]

\begin{tabular}{|c|c|c|}
\hline Challenge & Required Capabilities & SOA Governance Elements \\
\hline $\begin{array}{l}\text { Design decision } \\
\text { structure }\end{array}$ & $\begin{array}{l}\text { Determine service scope and } \\
\text { ownership } \\
\text { Define roles and responsibilities } \\
\text { Service Funding } \\
\text { Define shared services }\end{array}$ & $\begin{array}{l}\text { Governance Structure } \\
\text { (Roles and responsibilities, RACI chart...) } \\
\text { - Service Portfolio Management } \\
\text { (Service ownership, Service funding, service } \\
\text { definition...) }\end{array}$ \\
\hline $\begin{array}{l}\text { Define high value } \\
\text { business services }\end{array}$ & $\begin{array}{l}\text { Business process modeling } \\
\text { Determine IT services architecture } \\
\text { and evaluation metrics } \\
\text { Define shared services } \\
\text { Service portfolio management }\end{array}$ & Service Portfolio Management \\
\hline $\begin{array}{l}\text { Manage the life cycle } \\
\text { of assets }\end{array}$ & $\begin{array}{l}\text { Change management } \\
\text { Discovered, used and retired } \\
\text { service* policies } \\
\text { Required infrastructure for } \\
\text { organizing, discovering and } \\
\text { monitoring in service lifecycle }\end{array}$ & $\begin{array}{l}\text { Service Lifecycle Management } \\
\text { SOA Governance Technology (Repository, } \\
\text { Registry, Policy Management, etc) }\end{array}$ \\
\hline $\begin{array}{l}\text { Performance } \\
\text { evaluation and } \\
\text { measure effectiveness }\end{array}$ & $\begin{array}{l}\text { Business and IT dashboards } \\
\text { Performance metrics }\end{array}$ & Performance Assessment Metrics \\
\hline $\begin{array}{l}\text { Service compatibility } \\
\text { with standards, patterns } \\
\text { and policies }\end{array}$ & $\begin{array}{l}\text { Define shared services } \\
\text { Service deign and run time policy } \\
\text { management } \\
\text { Required infrastructure for } \\
\text { organizing, discovering and } \\
\text { monitoring in service lifecycle } \\
\text { Define governance processes }\end{array}$ & $\begin{array}{l}\text { Governance Lifecycle Management } \\
\text { (Design, Run and Change Time policy } \\
\text { Management) } \\
\text { SOA Governance Technology }\end{array}$ \\
\hline $\begin{array}{l}\text { Ensuring quality of } \\
\text { service }\end{array}$ & $\begin{array}{l}\text { Run time service monitoring } \\
\text { Design, run and change time } \\
\text { policies } \\
\text { Service level management }\end{array}$ & $\begin{array}{l}\text { Monitoring and Evaluation Processes } \\
\text { Governance Lifecycle Management }\end{array}$ \\
\hline
\end{tabular}

After defining a set of generic and critical SOA governance elements, six popular SOA governance frameworks [10-15] have been compared and analyzed 
International Journal of Managing Information Technology (IJMIT) Vol.4, No.3, August 2012

Table2: Comparison of SOA governance frameworks

\begin{tabular}{|l|c|c|c|c|c|c|c|}
\hline $\begin{array}{l}\text { SOA Governance } \\
\text { Elements }\end{array}$ & $\begin{array}{c}\text { CBDI } \\
\text {-SAE }\end{array}$ & Bieberstein & $\begin{array}{c}\text { Software } \\
\text { AG }\end{array}$ & $\begin{array}{c}\text { WebMethod } \\
\text { s }\end{array}$ & IBM & Oracle & COBIT \\
\hline $\begin{array}{l}\text { Service Lifecycle } \\
\text { Management }\end{array}$ & $\diamond$ & - & $\diamond$ & $\diamond$ & $\diamond$ & $\diamond$ & - \\
\hline $\begin{array}{l}\text { Governance } \\
\text { Lifecycle } \\
\text { Management }\end{array}$ & $\diamond$ & $\diamond$ & $\diamond$ & $\diamond$ & $\diamond$ & $\diamond$ & $\diamond$ \\
\hline $\begin{array}{l}\text { Monitoring and } \\
\text { Evaluation } \\
\text { Processes }\end{array}$ & $\diamond$ & $\diamond$ & $\diamond$ & $\diamond$ & $\diamond$ & $\diamond$ & $\diamond$ \\
\hline $\begin{array}{l}\text { Service Portfolio } \\
\text { Management }\end{array}$ & $\diamond$ & $\diamond$ & $\diamond$ & $\diamond$ & $\diamond$ & $\diamond$ & - \\
\hline $\begin{array}{l}\text { Performance } \\
\text { Assessment Metrics }\end{array}$ & $\diamond$ & $\diamond$ & - & - & $\diamond$ & $\diamond$ & $\diamond$ \\
\hline $\begin{array}{l}\text { Governance } \\
\text { Structure }\end{array}$ & $\diamond$ & $\diamond$ & $\diamond$ & - & $\diamond$ & $\diamond$ & $\diamond$ \\
\hline $\begin{array}{l}\text { SOA Governance } \\
\text { technology }\end{array}$ & $\diamond$ & $\diamond$ & $\diamond$ & $\diamond$ & $\diamond$ & $\diamond$ & $\diamond$ \\
\hline SOA Maturity & $\diamond$ & $\diamond$ & $\diamond$ & - & & $\diamond$ & - \\
\hline SOA Roadmap & $\diamond$ & $\diamond$ & $\diamond$ & - & $\diamond$ & $\diamond$ & - \\
\hline Best practice & - & $\diamond$ & $\diamond$ & $\diamond$ & $\diamond$ & $\diamond$ & $\diamond$ \\
\hline
\end{tabular}

Also, we have considered COBIT as a comprehensive IT governance framework in our comparison to see whether it supports the SOA governance elements or not. However, SOA governance is essentially different from IT governance, COBIT is a well accepted framework that has been implemented by many companies, and is based on IT service management approach [4]. It also completely addresses some critical SOA governance elements such as governance structure and evaluation processes. So, it supports the design of a governance model for SOA and can provide some guidance for designing a SOA governance framework. The results of these comparisons have been presented in table2. The comparison results showed that these frameworks are deficient in coverage SOA governance elements especially service portfolio management, SOA maturity, performance metrics and evaluation processes. The description of the SOA governance elements and also the details of comparison results can be found in [8]. This comparison suggests a design strategy that combines several frameworks into one and uses COBIT as starting point for the framework design process. We will describe briefly our idea in the next section.

\section{DESIGN: Development of the new Framework}

This section concerns the ideas and construction of a new framework for SOA governance that follows the main purpose and expectations of this study. The resulted framework is expected to promote the understanding of people i.e. stakeholders that are engaged in the establishment of a comprehensive, understandable, and meaningful model for deploying SOA. The most essential topics in SOA governance that have been identified as SOA governance elements can be placed 
International Journal of Managing Information Technology (IJMIT) Vol.4, No.3, August 2012

in a framework to ensure an appropriate transition from strategic considerations to delivery of the services. In the process of design, we have referred to the IT governance design framework defined by Weill and Ross [16] to define a good structure and foundation for effective governance. So, we have founded the new framework named AUT (Amirkabir University of Technology) SOA governance framework based on the architecture and concepts of this framework; however there are significant differences between IT governance and SOA governance. In our view, the concept of governance refers to control mechanisms and policy compliance. We need a control structure to clear policy development of services. The new framework should emphasize regulatory compliance throughout service lifecycle and define the path to follow when it is necessary to improve the level of control. As mentioned in the previous section, COBIT provides the control environment to manage processes regarding to key goals and performance indicators. Accordingly, in this study, the new framework is built upon COBIT framework that integrates a set of practical and proven control mechanisms with SOA prerequisites and supporting guidelines to deploy SOA in organizations. Although COBIT is an IT governance framework, we modify it by adding several practices and processes to examine items that are necessary to manage services such as:

- Maturity of service orientation within the enterprise

- Infrastructure enhancements for managing the usage of services in areas of security, monitoring, performance, versioning and shared usage

- Enhancements of IT processes to address funding, sharing and incentives for sharing, and reuse of services, as well as for the identification, design and specification of services

- Education and training

- Roles and responsibilities related to SOA processes

According to table1, the two most important SOA governance elements are service lifecycle management and governance lifecycle management. These elements include several processes for managing lifecycle of services and governing SOA. In AUT SOA governance framework, governance lifecycle processes have encompassed service lifecycle processes to support service management and provide ongoing SOA governance implementation. We have defined a set of possible checkpoints in service lifecycle processes and have considered evaluation processes and a vitality method for the policy compliance. The framework foundation defines a four-stage service lifecycle. It is based on service lifecycle of ITIL (IT infrastructure Library) framework [17]. Researches show that there are significant similarities between SOA service lifecycle and ITIL service management lifecycle [18]. ITIL provides the foundational layer to define processes for managing IT processes and capabilities needed to integrate each phase of service lifecycle to define and develop services; however, it is an IT governance framework and dose not thoroughly support all SOA governance elements such as SOA roadmap, SOA maturity and SOA governance technology. We extend ITIL service lifecycle by adding SOA processes and assigning decision rights, policies and measures around the services, processes and lifecycle of SOA to address such concerns as service registration, service ownership, service funding, service identification, service modeling, service publishing, service discovery, service development and service deployment.

SOA governance itself has a lifecycle that is distinct from the services that are being governed. In the proposed framework, SOA governance lifecycle is based on governance lifecycle of Open group SOA governance framework [2] .It is characterized as a four-stage process: Plan, Define, Implement and Measure. These actions are needed to establish, maintain, and enhance an affective SOA governance framework. 
International Journal of Managing Information Technology (IJMIT) Vol.4, No.3, August 2012

To improve understandability of the framework and simplifying its usage, a conceptual model (cf. Fig.1) has been developed that shows the main concepts of the new framework and their relationships. This model can be used by a typical practitioner as a guideline to discuss the SOA governance scope, and to clarify main concepts of the framework with their related terms. This model is mapped to the SOA governance focus areas which have been defined as SOA governance elements. As shown in Figure 1, the main concepts of the new framework have been subdivided to various aspects of governance such as SOA Governance Vision and Strategy, Processes and Organization, Architecture, Infrastructure and Policy compliance that are considered in four defined phases of governance lifecycle to support service lifecycle activities, and to provide ongoing governance implementation. The governance phases establish a model for managing service lifecycle activities that are categorized to four domains. These domains define activities that manage the design, development, testing and deployment of individual services and automated business processes. Service portfolio and solution portfolio have an impressive effect over service lifecycle from design and delivery of the IT service, to its operation and support.

The core components of AUT SOA governance framework are process domains, process management guidelines and a SOA adoption maturity model. In the following, each component of the framework is described:

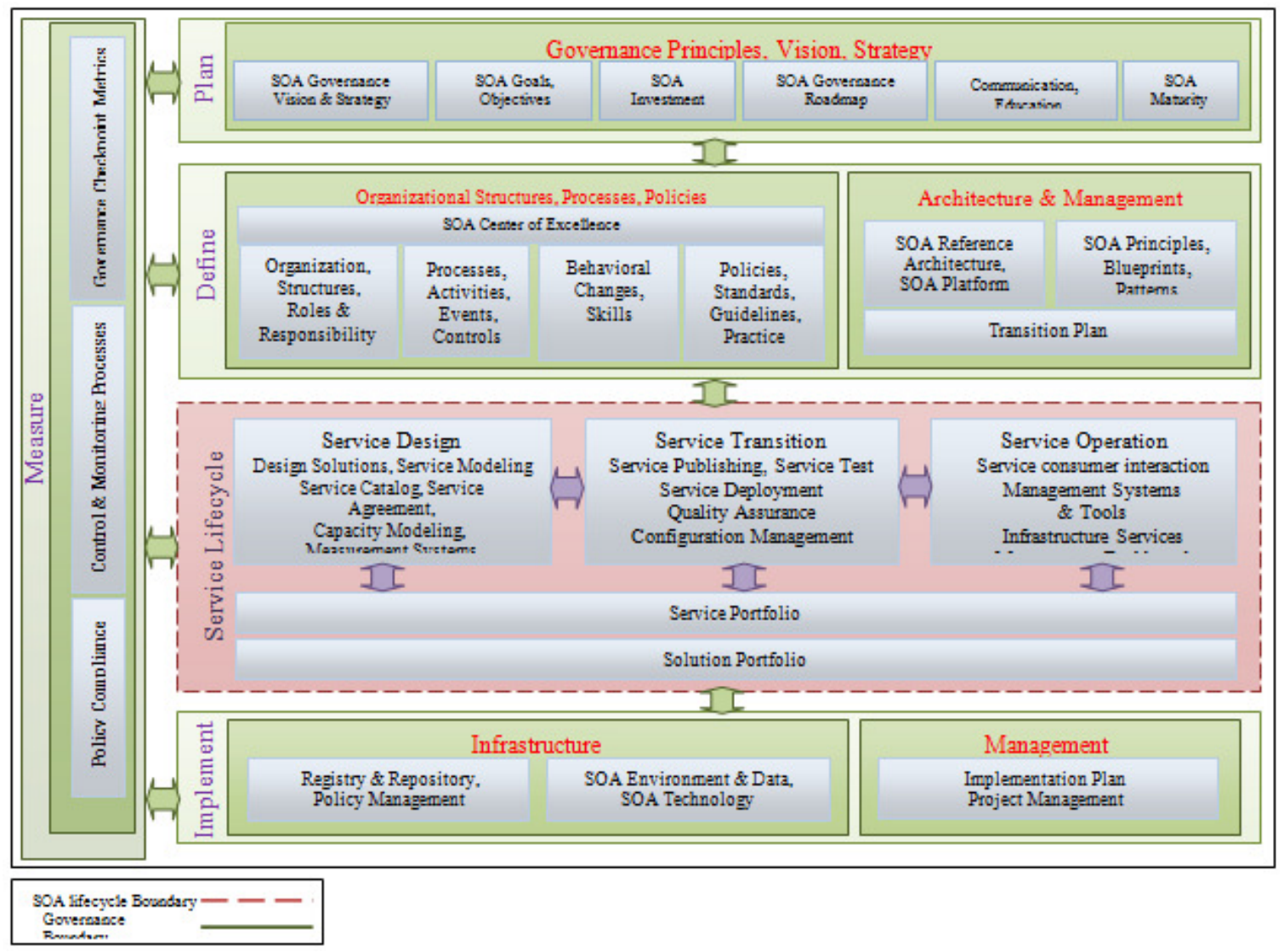

Figure 1: Conceptual Model of AUT SOA Governance Framework 
International Journal of Managing Information Technology (IJMIT) Vol.4, No.3, August 2012

\subsection{Process Domains}

Based on the two perspectives including governance and service lifecycle management approach, two process domains are distinguished. The process focus of the proposed framework subdivides relevant functions into four domains of governance lifecycle processes and four domains of service lifecycle processes. We have organized a complete set of vital processes in these process domains especially by adding evaluation and governing processes of COBIT, service management processes of ITIL and service production processes that have not been defined clearly in ITIL service lifecycle. Thus, a set of SOA governing processes and SOA governed processes and further detailed processes with clarified and measurable goals are defined across the SOA governance lifecycle and service lifecycle. The following sections details the SOA governance lifecycle and service lifecycle domains of the proposed framework with related their processes and activities.

\section{- Governance lifecycle}

As mentioned earlier, governance is responsible to ensure that certain predefined rules and policies are applied during the definition and development of services through the service lifecycle. In AUT SOA governance framework, governance processes are enabled across service lifecycle and provide checkpoints in multiple entry points of service lifecycle where policies are checked for compliance. Governance lifecycle consists of 10 processes categorized to four domains which are called Plan, Define, Implement and Measure. Governance lifecycle begins during the Plan phase and defines policies to guide implementation of the services and put a premium on automating the governance lifecycle. As shown in figure1, in the Plan phase of governance lifecycle, the strategic concepts such as SOA vision and strategy and SOA investment are determined and after maturity assessment, a SOA governance roadmap is provided. The Define phase focuses on determining organization and governance bodies and defining reference architecture, standards, patterns and required policies to manage SOA processes. Also, the gap between the current SOA governance and the target is analyzed and used to create a set of transition plans. These transition plans contain transformation initiatives for organizational, process, and technology areas that are required to deliver the objectives defined in the Plan phase. The Implement phase focuses on enabling and realizing the governance solutions determined in the Plan and Define phases. Hence, the SOA infrastructure including registry and repository, and also management aspects of the transition plans implementation are considered. In the Measure phase, evaluation processes and policy compliance are performed by using governance checkpoint metrics to determine whether the SOA governance framework is suited or needs to be changed. Table 3 shows an illustrative set of the defined processes for governance lifecycle.

Table3: Governance lifecycle processes

\begin{tabular}{|l|l|}
\hline Plan & PG1 :Define a SOA Strategic Plan \\
& PG2 :Manage Financial and SOA Investment \\
& PG3 :Manage Communication and Direction \\
\hline Define & DG1 :Define Transition Plans \\
& DG2: Define SOA Reference Architecture \\
& DG3 :Define SOA Processes, Organization and \\
& Relationships \\
\hline Implement & IG1 :Implement Transition Plans \\
& IG2:Enable Operation and Use \\
\hline Measure & MG1 :Monitor and Evaluate Performance \\
& MG2 :Manage Policy Compliance \\
\hline
\end{tabular}


International Journal of Managing Information Technology (IJMIT) Vol.4, No.3, August 2012

- Service Lifecycle

Service lifecycle processes manage the lifecycle of an IT service, from planning and optimizing services, the design and delivery of the IT service, to its operation and support. In AUT SOA governance framework, service lifecycle processes represent an area of SOA implementation, operation, maintenance, and management carried out by the governed processes. These processes are categorized to four domains which are called Service Strategy, Service Design, Service Transition and Service Operation. Totally, these domains define activities that govern the development, test and deployment of individual services and automated business processes. These activities are divided into two category including service production and service management processes. The majority of the service management aspects concentrate on registry, repository, metadata, policy management and operational aspects of services and SOA infrastructure. Service production processes are related to identify, design, implement, publish, deploy and support services. Also, service management processes such as service level management; event management and service monitoring and availability management are responsible to manage and monitor services and ensure quality of services. The later processes are fairly similar to the corresponding processes in COBIT. The main activity goals of service lifecycle processes are:

- Identifying and managing service domains and service funding

- Establishing a consistent approach to defining service based on the business process

- Designing of the technology architectures and management systems

- Establishing basic patterns and design guidelines

- Managing interaction with service consumers

- Monitoring service execution in relation to service contracts

- Identifying and managing all elements in the SOA infrastructure

- Managing change of services and SOA environment

Table 4 shows an illustrative set of processes for service lifecycle of the new framework.

Table4: Service lifecycle processes

\begin{tabular}{|l|l|}
\hline Service Production & SS1 : Solution Portfolio Management \\
Processes & SS2 : Service Portfolio Management \\
& SD1 : Service Modeling \\
& ST1 : Service Assembly \\
& ST3 : Service Deployment \\
& ST2 : Service Testing and Validation \\
& SO3 : Service and Infrastructure Support \\
\hline Service Management & SD2 : Service Level Management \\
Processes & SD3 : Service Capacity Management \\
& SD4 : Service Continuity Management \\
& SD5 : Security Management \\
& SD6 : Service Availability Management \\
& ST4 : Change Management \\
& ST5 : Configuration Management \\
& SO1 : Event Management and Service \\
& Monitoring \\
& SO2: Data Management \\
\hline
\end{tabular}

The overall AUT SOA governance framework can be shown graphically, as depicted in Figure. 2, with a process model containing 26 generic processes, managing services and delivering information to the business according to business and governance requirements. Managing 
International Journal of Managing Information Technology (IJMIT) Vol.4, No.3, August 2012

service lifecycle is at the heart of the proposed framework and ensures aligning IT services with business requirements. Governance processes have encompassed service lifecycle processes to support service management and provide iterative SOA adoption maturity assessment and ongoing SOA governance implementation. It provides a common reference model understandable to users and practitioners.

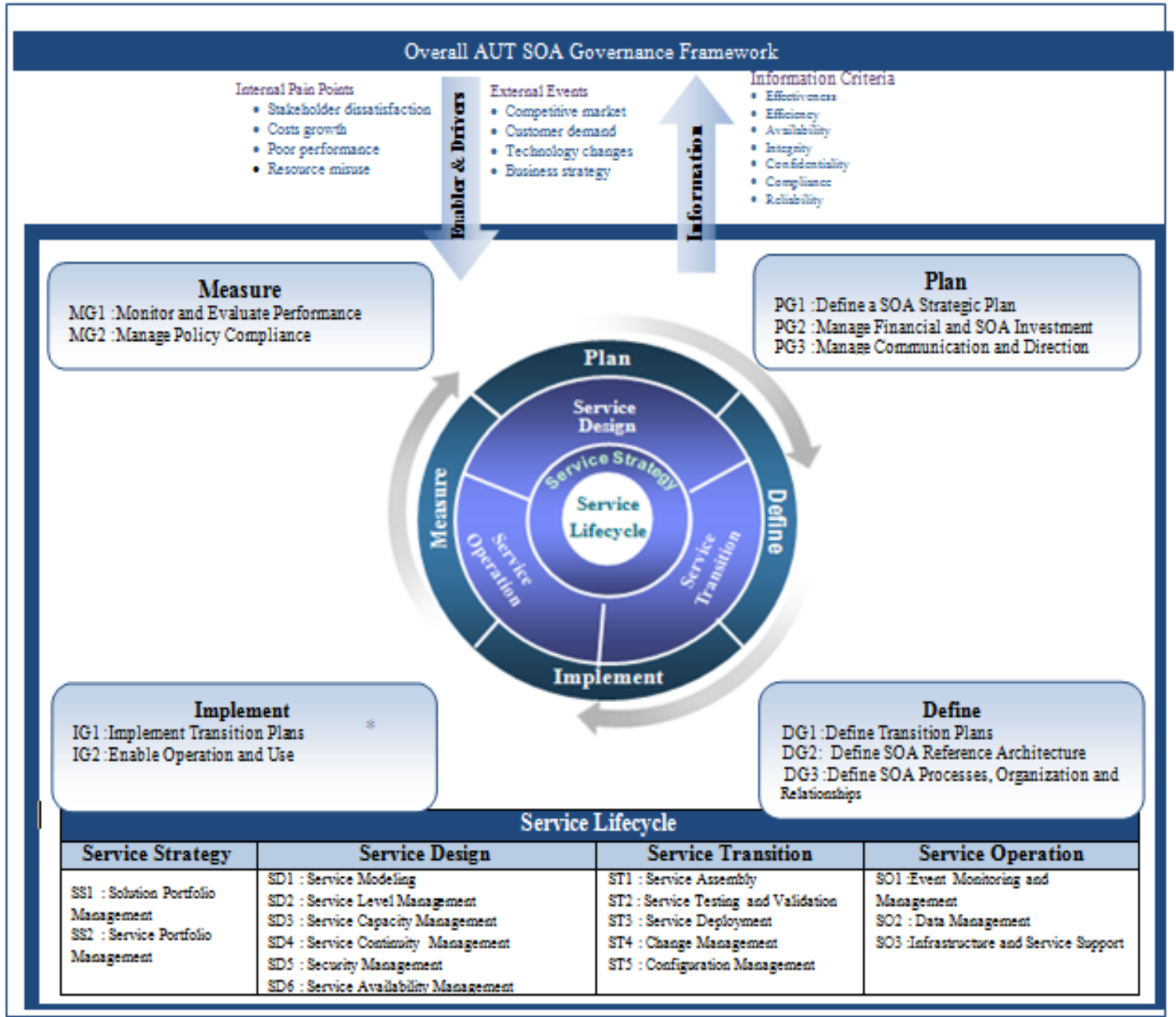

Figure 2: AUT SOA Governance Framework

\subsection{Process Management Guidelines}

AUT SOA governance follows the high-level structure of process description, similar to the COBIT framework. It consists of a set of guiding principles and a number of processes conforming to those principles, which are further defined as a suite of process management guidelines. As mentioned in the previous section, a major shortcoming of the existing SOA governance frameworks is that they have not provided usefully reference guide for application the framework and most of them have made less attention to clarify the processes, application controls and metrics to measure performance. AUT SOA governance framework uses a wellorganized process to clearly explain processes of the framework. In the proposed framework, each process has a process description, key activity goals, activities, metrics, process inputs and 
International Journal of Managing Information Technology (IJMIT) Vol.4, No.3, August 2012

outputs. Also the framework defines a set of control objectives for all 26 processes, as well as roles and responsibilities and application controls. As a whole, these are the characteristics of a well-managed process. Each process is one of the SOA governing processes or SOA governed processes which are arranged according to two separate lifecycles. A process is a structured set of activities designed to accomplish a specific objective. The process activity gives a detailed description of what is done that may also define a set of procedures and work instructions. Each process provides a set of control objectives which define what needs to be done to implement effective control procedures in the process. These control procedures define policies, guidelines or critical success factors (CSF) to successfully execution of the process. It means AUT framework directs its control mechanisms by control objectives that focus on what is done in the process. A process needs resources and capabilities to support properly control and management based on the process control objectives. Furthermore, the set of goals are defined for each process, which can be divided into process goals and activity goals for getting process under control and enabling effective process performance. Each goal is measured with the aid of different metrics (key performance indicators). Process implementation will be in place at different maturity levels that are determined by using a process maturity model. For effective and efficient execution of the activities and accountability for the process end deliverables, roles and responsibilities are specified in RACI charts. Finally, a process takes one or more inputs and turns them into defined outputs.

Based on this structure, we have provided the description of all processes and a complete set of control objectives for each process. We have defined more than 290 control objectives for processes of the framework that broadly specify related instruction works, activities and policies for each process. Each process has at least 10 control objectives. For example: Determining an enterprise data management function to define and monitor enforcement of data governance has been considered as a control objective for the Data Management process of the Service Operation domain. Also, establishing an identity system to determine and control rights and responsibility in the registry/ repository is a defined control objective for the Security Management process of the Service Design domain.

Due to lack of space we will not discuss each process description, the set of control objectives of each process, RACI chart and process maturity model. Such a discussion will be published in the future papers.

\subsubsection{Proposed Maturity Model for the Framework}

In transition to SOA, organizations need to assess where they are in the migration path to SOA and how to achieve greater benefits to support the organization, business and systems. In order to achieve SOA benefits associated with higher levels of maturity, AUT SOA governance framework provides a SOA adoption maturity model. It has been defined based on Open Group Service Integration Maturity Model [19]; however, we have customized this model to define SOA adoption requirements and prerequisites in six dimensions across five maturity levels. The six dimensions are Organization, Process, Governance, Service and Service management, Architecture, Infrastructure and the Business View that are specified based on the defined concepts of the conceptual model. The five maturity levels are Initial, Managed, Defined, Quantitatively managed and Optimizing, which are based on CMMI maturity levels. Moreover for management and control over the framework processes, we can use the COBIT process maturity model. It enables the assessment of process capability as well as benchmarking and identification of necessary capability improvements. This maturity model specifies principles of the attributes including Awareness and communication, Policies, plans and procedures, Tools 
International Journal of Managing Information Technology (IJMIT) Vol.4, No.3, August 2012

and automation, Skills and expertise, Responsibility and accountability and Goal setting and measurement [4]. These attributes are the characteristics of process management and describe how they evolve from a non-existent to an optimized process. By incorporating these maturity models in the framework, it is possible to establish SOA governance in an incremental manner.

\section{Demonstration: Applying the Proposed Framework in a Case Study}

To demonstrate the general applicability of our framework, we have done an extensive case study at an IT department where we could model a part of the framework with a focus on analyzing business objectives, IT strategy, processes and capabilities of organization. This section provides a case study of a real example of SOA governance in practice by using the framework in an IT department of Isfahan Municipality.

\subsection{Introducing ICTIM}

Information \& Communication Technology Department of Isfahan Municipality (ICTIM) has been founded since 1981 with the objective of providing a wide variety of automated and on line services to all departments of Isfahan municipality. The services are typically IT applications and infrastructure that are packaged and offered as services by internal IT staff or external service provider. Recently, ICTIM has been implementing IT governance using ITILv3 for two years. It has implemented an improved service level management process and a new service management system that address service request, incident and problem management, policies and procedures based on ITIL guidance. In addition, an IT security policy and procedure is near completion, and a new configuration management system will be rolled out later in the next year. ICTIM had several challenges to develop and support IT services. In the following, the most important challenges that ICTIM faced them in delivering applications and services are described:

- The existing applications and ICTIM itself operate in silos. This environment currently relies on a point-to-point integration architecture, which is costly, time consuming and rigid when the business requires change.

- IT landscape grew significantly for the last years. Such a huge, distributed and complex infrastructure is not easy to maintain especially concerning the core business processes.

- The organization lacks a development methodology and governance, which is sorely needed to support the re-use of existing application components and flexible services across the organization.

- The governing body has very little control and power over the development groups, project management teams and IT staff

To resolve these challenges, the organization decided to apply a service orientation approach to modernize its IT infrastructure and enhance their business process automation as well as the ability to rapidly respond to business process changes. Towards this objective, the organization must follow a standardized method and govern implementations. Since the SOA governance journey is an incremental process, we have proposed an implementation process to simplify the application and implementation of the framework. This process (shown in Figure. 3) helps move a company forward in its SOA governance capabilities. 
International Journal of Managing Information Technology (IJMIT) Vol.4, No.3, August 2012

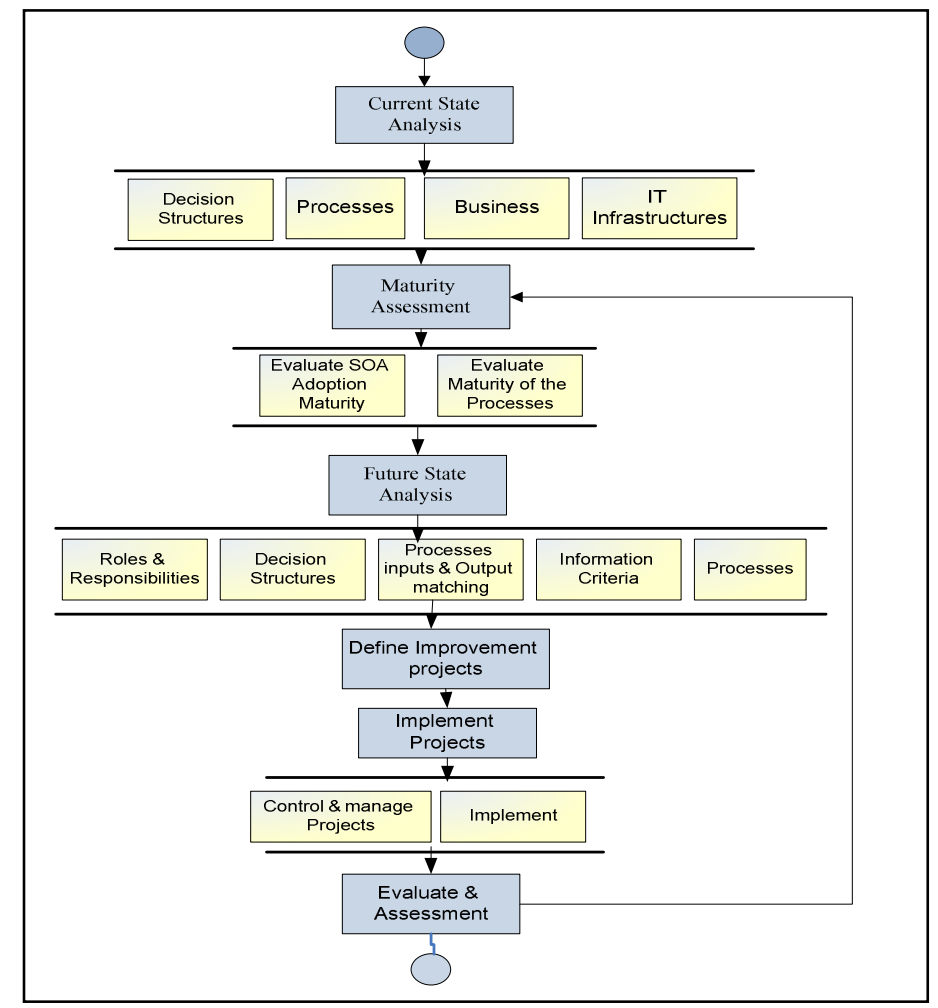

Figure 3: The Implementation process for the framework

In the case study, the implementation scope was limited to some activities and deliverables related to implementation steps presented in figure 3 in the following focus areas:

\subsection{Current State Analysis}

Understanding and analyzing the ICTIM environment in the following domains:

\section{Business}

- Esfahan municipality's needs as part of business strategy

- Business processes that have the highest impact and value to the users

- Business process priorities - for the business processes and for each process area. The top priorities are addressed in the transition plans.

\section{Processes}

- The key processes of service lifecycle to address.

- Process owners with clear roles and responsibilities.

\section{Decision Structures}

- Managerial structure of the organization and its units, decision structures and related roles Infrastructure

- Service registry, security, monitoring tools, servers, portal, technologies, test standards

\subsection{Maturity assessment}

- Evaluation of the readiness and maturity of organization to provide efficient service oriented architecture and utilize SOA infrastructure

- Evaluation of the ICTIM processes maturity 
International Journal of Managing Information Technology (IJMIT) Vol.4, No.3, August 2012

As the second step, we evaluated ICTIM SOA maturity by filling out the questioner that we have provided it based on SOA adoption maturity model of the framework. The questionnaire consists of thirty questions which are about 6 aspects of organization SOA readiness. We recognized that the SOA maturity level of ICTIM is around 1.4. Also, ICTIM undertook process maturity assessments for service lifecycle processes based on the framework s service lifecycle by using process maturity model. The average of processes maturity rate was 1.7.

\subsection{Gap Analysis and Future State}

The purpose of this step is specifying and analyzing current state versus desired state and determining what it would take to move from current to desired state. According to the obtained results of maturity assessment and also, mission and strategy of ICTIM, the SOA team set priorities and defined several activities to be done. The overall results of these analyses which are classified based on the elements of AUT framework are in the following:

- Governance structure( decision structure and roles and responsibilities)

The first phase concerns the alignment of the strategic planning to the organizational context. Because there were no SOA governance bodies in ICTIM ,creating clear SOA governance bodies by assigning responsibilities and establishing project groups will lead to a structured approach in SOA deployment. So, ICTIM Initiated a SOA Core team including group of business and SOA IT enablement expertise that operate as a centre of excellence $(\mathrm{CoE})$ and help realize the benefits of SOA by providing advice, guidance and standards to projects. The second requirement was revising organization chart to apply new roles such as architect, security manager and portfolio manager for related processes in service lifecycle processes of the framework.

\section{- Processes}

Although ICTIM uses ITIL service lifecycle processes to organize and manage IT activities, some of the SOA processes of AUT framework such as solution portfolio management, service portfolio management, infrastructure and service support have not been defined in ICTIM or do not have enough maturity to implement the framework. According to a high-level assessment of ICTIM functions, six process areas were initially identified as key risk points: Service Portfolio Management (SS2), Define SOA reference architecture (SD7), Change Management (ST4), Service Level Management (ST5), Infrastructure and Service Support (SO3) and Monitor and Evaluate Performance (ME1). Because there is no systematic method in ICTIM for evaluating performance of the processes, the defined processes of the measure phase of governance process domains should be considered to define relevant performance indicators and timely reporting of performance. The SOA team focused on implementing defined key control objectives of these processes. In the initial step, the primary areas of governance to be addressed are simple policies and procedures that are most about architecture, service portfolio and service operations. Other governance aspects require more maturity and will be considered in the next iterations. For regularly assessment quality of processes and compliance with control requirements, ICTIM set up ongoing governance and monitoring processes to support control sustainment and to mature of the processes.

\section{- SOA roadmap}

Based on the governance lifecycle processes defined in the new framework, the organization needs to govern activities for defining transition plans and the SOA roadmap. Therefore an intuitive SOA roadmap was established to guide organization through a path of technical, architectural and organizational resistance. The defined roadmap has considered three distinct phases covering 36 months. However, to completely deploy SOA governance capabilities and to develop required services for all business domains of municipality, more than the predicted time is required. At first phase of the roadmap, ICTIM focused on modernizing and transitioning value 
International Journal of Managing Information Technology (IJMIT) Vol.4, No.3, August 2012

added existing systems to SOA and providing SOA guidelines, integrating platforms and infrastructure to develop new applications and Also, implementing the required processes to support SOA activities.

- Service Portfolio management

ICTIM has no defined activity or process to identify and manage services. Developing service portfolio management of service strategy phase ensures that a sound method is used consistently to decide which services need to be developed and how the necessary investments are prioritized. Therefore, ICTIM used Microsoft SharePoint to design and implement a service portfolio and define relevant procedures and activities.

- Implementing control mechanisms

In order to achieve adequate management and control of services, ICTIM should put service lifecycle processes under control. Toward this objective, ICTIM applied control procedures based on the defined control objectives of the service lifecycle processes to govern creating new services, reusing existing services and enforcing standards and best practices across ICTIM. Also in order to discover web services and usage of services in the repository, some tools and custom codes were used. If there were opportunities for improvement, the governance team would engage in conversations with the service owners to coach and mentor them on the proper design and deployment of their services.

- SOA Governance technology

In the field of technology and infrastructure, the necessary technology and facilities should be placed in ICTIM that enable governance and the whole or partial automation of the governing processes. Technology capabilities can be used by the governing processes especially service operation processes. The SOA team proposed a planned approach to acquisition, implement and maintenance of infrastructure. The relevant activities include:

- Apply policy enforcement capability to support and possibly automate the monitoring for violations of governance policy.

- Provide and deploy SOA management tools such as change control or configuration management to implement and maintain governance.

- Plan and design a service registry

- Define SOA architecture to define service architecture and blueprint comprising logical architecture and as-is/to-be functional architectures

- Monitor and manage service events to ensure services are monitored by the SOA infrastructure and to collect SOA metrics and analyze usage, performance and errors

In addition to these activities, ICTIM decided to develop a portal application as a SOA pilot project to serve citizens by providing some common services such as Tax Bill Create, Building Permission View and Electronic Payment. Instead of creating specific application logic for each of the different applications, the SOA team could take advantage of this opportunity to create an SOA-based application.

\subsection{Evaluation and Assessment the cast study results}

ICTIM periodically evaluated efficiency and effectiveness of the framework at predefined intervals in the roadmap by reviewing performance against targets, analyzing the cause of any deviations, and initiating remedial action to address the underlying causes. The evaluation could be done in the following distinctive aspects:

- Maturity assessment by using the process maturity model

This is done by using process maturity model and filling out the questioners for each process and the state and maturity of the processes are assessed and gaps are identified. 
International Journal of Managing Information Technology (IJMIT) Vol.4, No.3, August 2012

- Measuring the information criteria coverage

According to the framework process model (shown in Figure. 2) seven major principles have been defined as information criteria (same as COBIT). These criteria provide a basis for defining the business requirements and developing the metrics that allow measurement against defined goals. In this assessment, the scale of information criteria coverage is evaluated through defining KPIs for each process related to information criteria and filling out the relevant questioners. Since the criteria of Availability, Integrity, Efficiency and Effectiveness are more important for ICTIM, in the first iteration of the implementation, ICTIM considered the control objectives of related service lifecycle processes to increase these criteria.

- Matching the processes inputs \& outputs

The inputs and outputs of each process have been defined in the process management guidelines. The organization should consider and use these processes description while defining each process and should place control mechanisms based on the defined control objectives for the processes. By using these guidelines ICTIM could control the processes status and analyze gap and mismatches especially in inputs and outputs of the processes.

\subsection{Lessons Learned}

After successfully performing the defined activities and the associated service infrastructure, ICTIM has gained much useful experience and tends to move to a more service-based approach . Web services are being used to help integrate backend systems with measurable platforms and create a portfolio of services. By implementing the governance checkpoints and procedures across service lifecycle, ICTIM can obtain value from:

- Governing new service creation and determining priorities and funding for the establishment of services.

- Identifying who owns services and driving better requirements against services to reuse by establishing service level agreements.

- Ensuring that services are adhering to standards and best practices, thereby reducing risks across deployment and management.

- Ensuring that there is a consistent service change management capability and a more refined, explicit versioning process for services.

This practice provided a sound foundation for the next step of the framework deployment.

\section{Evaluation: Qualitative Evaluation of AUT SOA Governance Framework}

We have used common techniques such as comparison with existing frameworks and qualitative evaluation for evaluating the proposed framework. Table 5 presents a comparison that has been made among AUT SOA governance framework and its counterparts. We have used SOA governance elements presented in table1 as evaluation criteria to assess AUT SOA governance framework. The results of this first qualitative evaluation express that the proposed framework includes all imperative elements of SOA governance specially service portfolio management, SOA roadmap, performance metrics and evaluation processes that have been less detailed in other frameworks. 
International Journal of Managing Information Technology (IJMIT) Vol.4, No.3, August 2012

Table5: Evaluation of AUT SOA governance framework

\begin{tabular}{|c|c|c|c|c|c|c|c|c|}
\hline SOA Governance Elements & $\begin{array}{l}\text { CBDI } \\
\text {-SAE }\end{array}$ & $\begin{array}{l}\text { Bieberste } \\
\text { in } \\
\end{array}$ & $\begin{array}{c}\text { Software } \\
\text { AG }\end{array}$ & $\begin{array}{c}\text { WebMetho } \\
\mathrm{ds} \\
\end{array}$ & $\begin{array}{l}\text { IB } \\
\text { M }\end{array}$ & $\begin{array}{c}\text { Oracl } \\
\mathrm{e}\end{array}$ & $\begin{array}{c}\mathrm{COBI} \\
\mathrm{T}\end{array}$ & $\begin{array}{c}\text { AUT } \\
\text { Framework }\end{array}$ \\
\hline $\begin{array}{l}\text { Service Lifecycle } \\
\text { Management }\end{array}$ & $\diamond$ & Ht & $\bullet$ & 4 & $\bullet$ & $\diamond$ & - & 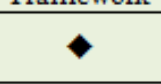 \\
\hline $\begin{array}{l}\text { Govemance Lifecycle } \\
\text { Management }\end{array}$ & $\bullet$ & $\diamond$ & $\bullet$ & $\bullet$ & $\bullet$ & $\diamond$ & $\bullet$ & $\bullet$ \\
\hline $\begin{array}{l}\text { Monitoring and Evaluation } \\
\text { Processes }\end{array}$ & $\diamond$ & $\diamond$ & $\diamond$ & $\diamond$ & $\diamond$ & $\bullet$ & $\bullet$ & $\bullet$ \\
\hline Service Portfolio Management & $\Delta$ & $\Delta$ & $\Delta$ & $\Delta$ & $\Delta$ & $\Delta$ & & $\bullet$ \\
\hline $\begin{array}{l}\text { Performance Assessment } \\
\text { Metrics }\end{array}$ & $\diamond$ & $\diamond$ & - & - & $\diamond$ & $\diamond$ & $\diamond$ & $\bullet$ \\
\hline Govemance Structure & $\Delta$ & $\bullet$ & $\bullet$ & - & $\Delta$ & $\bullet$ & $\bullet$ & $\diamond$ \\
\hline SOA Govemance technology & $\bullet$ & $\Delta$ & $\bullet$ & $\bullet$ & $\diamond$ & $\bullet$ & $\Delta$ & $\Delta$ \\
\hline SOA Maturity & $\bullet$ & $\Delta$ & $\bullet$ & - & & $\bullet$ & - & $\bullet$ \\
\hline SOA Roadmap & $\diamond$ & $\bullet$ & $\diamond$ & - & $\diamond$ & $\diamond$ & - & $\bullet$ \\
\hline Best practice & - & $\bullet$ & $\bullet$ & $\diamond$ & $\bullet$ & $\bullet$ & $\bullet$ & $\bullet$ \\
\hline
\end{tabular}

In the second evaluation, we have provided a qualitative model to examine the various aspects of AUT SOA governance framework. This model focuses on concepts and properties, findings, process and pragmatics. We have devised this model with a particular focus on the methods used most extensively in evaluations and a review of existing frameworks for assessing quality in qualitative research [20][21][22]. The evaluation model has been thoroughly defined in [23].Table6 lists the selected quality criteria of our evaluation. They cover all of the key features and processes involved in qualitative enquiry. The qualitative model begin with assessment of the findings, move through different stages of the research process (design, analysis and evaluation) and end with some general features of research product (understandability, applicability, ...)

Table6: Description of Criteria for Qualitative assessment

\begin{tabular}{|l|l|}
\hline $\begin{array}{l}\text { Quality } \\
\text { Criterion }\end{array}$ & Description \\
\hline Finding & $\begin{array}{l}\text { Finding refers to a particular result of the research. The result may be a specific procedure } \\
\text { or technique, framework, architectural style, analytic model or specific solution for software } \\
\text { development or for analysis [24]. }\end{array}$ \\
\hline Process & $\begin{array}{l}\text { A development process is a series of actions and steps that are performed to propose the } \\
\text { new framework } \\
\text { [21]. This criterion deals with the process development aspect of the proposed framework } \\
\text { and methodology of the design. }\end{array}$ \\
\hline Pragmatics & $\begin{array}{l}\text { Pragmatics refers to practical aspects of deploying and using a methodology / framework / } \\
\text { model [22]. This criteria deal with pragmatics of adopting the proposed framework for a } \\
\text { project or within an organization. }\end{array}$ \\
\hline $\begin{array}{l}\text { Concepts } \\
\text { Properties }\end{array}$ & $\begin{array}{l}\text { A concept is an abstraction derived from specific instances within a problem domain. A } \\
\text { property is a special capability or characteristic [22]. For the proposed framework, these } \\
\text { include some concepts derived from SOA governance domain. }\end{array}$ \\
\hline
\end{tabular}

Table7 presents the devised qualitative model to evaluate AUT SOA governance framework. For each criterion, we have identified relevant sub criteria with a comprehensive review of the literature [22], [25], [26] and [27] on qualitative research methods elevating to standards in qualitative research and have matched them with the designed framework. Some of the questions 
International Journal of Managing Information Technology (IJMIT) Vol.4, No.3, August 2012

have been suggested for appraisal. The last column describes summary of our evaluation based on criteria.

Table7: Qualitative Evaluation of AUT SOA Governance Framework

\begin{tabular}{|c|c|c|c|}
\hline 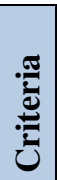 & Sub Criteria & Assessment questions & Description \\
\hline & $\begin{array}{l}\text { Understanda } \\
\text { ble }\end{array}$ & $\begin{array}{l}\text { How findings have } \\
\text { contributed to } \\
\text { knowledge/understand } \\
\text { ing (e.g. of the } \\
\text { framework, } \\
\text { governance structures, } \\
\text { process domains and } \\
\text { related components) }\end{array}$ & $\begin{array}{l}\text { AUT SOA framework is basically easy to understand } \\
\text { and use. The framework elements are defined via a } \\
\text { logical well-define structure that present some guidance } \\
\text { to those who would like to understand it. The behavior } \\
\text { of the framework is introduced via a conceptual model } \\
\text { and a meta model which reduce overall complexity and } \\
\text { help perceive the implications of the proposed } \\
\text { framework. So it becomes free from obscurity and easy } \\
\text { to understand. }\end{array}$ \\
\hline & Contribution & $\begin{array}{l}\text { Has the framework } \\
\text { offered } \\
\text { guidance } \\
\text { researchers for future } \\
\text { works? }\end{array}$ & $\begin{array}{l}\text { AUT SOA framework is expandable across its main } \\
\text { components. This research offers guidance for future } \\
\text { action or changing it to improve and provide an } \\
\text { interesting basis for future research. For example } \\
\text { defining a set of control practices for each defined } \\
\text { control objective the same as COBIT or applying the } \\
\text { balanced scorecard (BSC) approach to evaluate } \\
\text { performance of the processes are two future } \\
\text { contributions of the framework. }\end{array}$ \\
\hline : & $\begin{array}{l}\text { Expressivenes } \\
\text { s }\end{array}$ & $\begin{array}{l}\text { How well is the } \\
\text { framework } \\
\text { architecture/structure? } \\
\text { How well have the } \\
\text { framework elements } \\
\text { been defined? }\end{array}$ & $\begin{array}{l}\text { The framework architecture is based on COBIT, ITIL } \\
\text { and IBM which are well accepted frameworks. The } \\
\text { governance structures, control mechanisms, processes, } \\
\text { measurement metrics and all related elements within the } \\
\text { framework have been presented explicitly and defined in } \\
\text { details. Also, the framework elements and their } \\
\text { relationships have been represented in a meta model by } \\
\text { using UML notation that makes the framework more } \\
\text { expressiveness }\end{array}$ \\
\hline \multirow{3}{*}{ 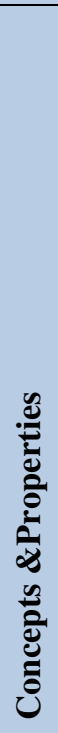 } & Manageable & $\begin{array}{l}\text { Dose the framework } \\
\text { determine control } \\
\text { structures and } \\
\text { mechanisms? } \\
\text { How controls can be } \\
\text { implemented within } \\
\text { framework for all } \\
\text { defined processes? }\end{array}$ & $\begin{array}{l}\text { AUT SOA provides good practices across a domain and } \\
\text { process framework and presents activities in a } \\
\text { manageable and logical structure. They are strongly } \\
\text { focused more on control, less on execution. By defining } \\
\text { more than } 290 \text { control objectives for processes of the } \\
\text { framework, the management requirements for effective } \\
\text { control of each process have been broadly provided. }\end{array}$ \\
\hline & $\begin{array}{l}\text { Comprehensi } \\
\text { ve }\end{array}$ & $\begin{array}{l}\text { How well does the } \\
\text { framework address } \\
\text { SOA governance } \\
\text { elements? }\end{array}$ & $\begin{array}{l}\text { Based on the obtained results of the first evaluation } \\
\text { (presented in Table 5), all imperative SOA governance } \\
\text { elements that existing frameworks do not completely } \\
\text { cover them especially SOA roadmap, service lifecycle } \\
\text { and evaluation processes have been considered in the } \\
\text { proposed framework. So, it becomes a more } \\
\text { comprehensive SOA governance framework which } \\
\text { addresses SOA adoption requirements. }\end{array}$ \\
\hline & $\begin{array}{l}\text { Well- } \\
\text { Documentati }\end{array}$ & $\begin{array}{l}\text { Have all } \\
\text { framework }\end{array}$ & $\begin{array}{l}\text { In the proposed framework all processes, their } \\
\text { relationships, related roles and responsibilities, }\end{array}$ \\
\hline
\end{tabular}


International Journal of Managing Information Technology (IJMIT) Vol.4, No.3, August 2012

\begin{tabular}{|c|c|c|c|}
\hline & on & $\begin{array}{l}\text { components and their } \\
\text { related elements been } \\
\text { expressed clearly? } \\
\text { How adequately has } \\
\text { the framework } \\
\text { elements been } \\
\text { documented? }\end{array}$ & $\begin{array}{l}\text { activities, activity goals, measurement metrics and } \\
\text { control objectives have been entirely documented and } \\
\text { clarified in a well-defined structure as processes } \\
\text { management guidelines. }\end{array}$ \\
\hline \multirow[b]{2}{*}{ 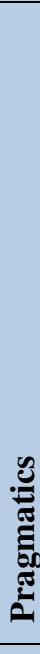 } & Easy to use & $\begin{array}{l}\text { Is the framework easy } \\
\text { to use? } \\
\text { Do the framework } \\
\text { concepts rolve } \\
\text { properties } \\
\text { easily? }\end{array}$ & $\begin{array}{l}\text { From an empirical study of the framework, AUT SOA } \\
\text { looks being simple to use. We have provided an } \\
\text { implementation process that introduces some important } \\
\text { steps to implement the framework and help to move a } \\
\text { company forward in its SOA governance capabilities. } \\
\text { We have provided best practices for each step of the } \\
\text { process. }\end{array}$ \\
\hline & Applicability & $\begin{array}{l}\text { Dose the framework } \\
\text { adhere to the intended } \\
\text { problem domain? } \\
\text { Is the use of the } \\
\text { framework suitable for } \\
\text { a particular } \\
\text { application domain? }\end{array}$ & $\begin{array}{l}\text { The framework has been provided based on analyzing } \\
\text { existing frameworks and identifying the shortcoming of } \\
\text { them. Also, it is based on COBIT that is a well-accepted } \\
\text { and applicable framework that has been implemented by } \\
\text { many companies. By applying governance structure, } \\
\text { management and control mechanisms of COBIT and } \\
\text { focus on the existing defects and challenges, the } \\
\text { proposed framework can be a credible and applicable } \\
\text { framework. }\end{array}$ \\
\hline \multirow[b]{3}{*}{ 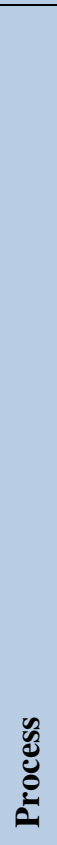 } & $\begin{array}{l}\text { Design } \\
\text { Methodology }\end{array}$ & $\begin{array}{l}\text { How defensible is the } \\
\text { design process? } \\
\text { Is methodology useful } \\
\text { in creating new } \\
\text { software, prototyping, } \\
\text { or designing new } \\
\text { model /framework? }\end{array}$ & $\begin{array}{l}\text { The framework is designed by following the design } \\
\text { science research methodology (DSRM) presented by } \\
\text { Peffers et al. [6] and using the guidelines for design } \\
\text { science defined by Hevner et al. [7]. DSRM is used by } \\
\text { many practitioners to design new artifact. }\end{array}$ \\
\hline & $\begin{array}{l}\text { Lifecycle } \\
\text { coverage }\end{array}$ & $\begin{array}{l}\text { Dose design process } \\
\text { involves all the } \\
\text { development stages? } \\
\text { How well does the } \\
\text { process cover the } \\
\text { whole lifecycle } \\
\text { development? }\end{array}$ & $\begin{array}{l}\text { The design process covers all stages of design the new } \\
\text { framework.. This process involves problem definition } \\
\text { (Requirements gathering), define strategy (Analysis), } \\
\text { design, demonstration (implementation) and evaluation } \\
\text { (testing) within the development lifecycle. }\end{array}$ \\
\hline & Evaluation & $\begin{array}{l}\text { How has been the } \\
\text { framework evaluated? } \\
\text { How good is the } \\
\text { sample/ case study } \\
\text { defensible? }\end{array}$ & $\begin{array}{l}\text { Three common techniques(case study, qualitative } \\
\text { analysis and testing methods) based on design science } \\
\text { research guidelines for evaluating the proposed } \\
\text { framework have been used. } \\
\text { Also, we have applied the framework in an IT } \\
\text { department to resolve some IT and business challenges } \\
\text { related to SOA governance in an incremental approach. }\end{array}$ \\
\hline
\end{tabular}

\section{SUMMARY}

Despite the wide range of advantages which are associated with the introduction of a serviceoriented architecture, there are a set of implications for adopting this approach and most organizations face significant challenges and obstacles in their SOA implementation. To successfully implement SOA and to address the existing challenges and capture maximum benefits of SOA, organizations need precise definition of processes, control mechanism, SOA 
International Journal of Managing Information Technology (IJMIT) Vol.4, No.3, August 2012

metrics and enforcement of policies that are mainly defined in SOA governance frameworks [28]. A SOA governance framework defines the set of processes, organization structure, policies, solutions and technologies that can help manage complex SOA deployment in an effective and efficient manner [2]. So, some enterprises have made a SOA governance framework as an imperative part of any SOA implementation in their organization. While there are several SOA governance frameworks to serve SOA adoption in organizations, our analysis showed that they are deficient in coverage some important elements of SOA governance such as SOA roadmap, service portfolio and service lifecycle processes and also they do not completely document all processes and their relationships, measurement metrics and related roles and responsibilities. In this paper, we have followed the design science methodology to develop a new more comprehensive framework that entirely covers all imperative elements of SOA governance. The proposed framework incorporates principles, practices, and procedures required to carry out SOA governance and meet the following objectives:

- It is an applicable framework that is consistent with the successful IT governance frameworks such as COBIT and ITIL.

- It provides a generic process model that represents a complete set of necessary SOA governance processes by combining governance processes of COBIT with ITIL service lifecycle and applying a set of SOA activities, SOA technology and SOA governance structure.

- It defines the description of 26 processes and related elements including activity goals, activities, inputs and outputs and metrics in a logical structure and also provides more than 290 control objectives to effective control of the processes

We have evaluated the framework by comparing with SOA governance elements and analyzing with a proposed extensive qualitative model to examine the various aspects of AUT SOA governance framework. The evaluation results reveal that the new framework is comprehensive enough and covers all necessary elements specially service portfolio management, SOA roadmap and evaluation processes that the existing frameworks have not completely covered.

Using SOA and service management best practices and defining the description of processes and management control objectives in a well-defined structure, make the proposed framework more manageable and expressive.

By means of a proposed implementation process, we demonstrated the application of the designed framework in an IT service department. Although further case studies should be done to monitor the application of our framework in multiple projects and its further verification

As a future work, we will integrate the proposed framework and balanced scorecard (BSC) approach as a performance measurement system to establish objectives, metrics and a baseline for assessment of process maturity. It can be used as generic SOA governance balanced scorecard for improving SOA governance performance.

\section{REFERENCES}

[1] Erl T. (2005). Service-Oriented Architecture: concepts, technology and design, Prentice Hall, Upper Saddle River

[2] Open Group.(2009). Electronic Publication, SOA Governance framework, Technical Standard

[3] Oracle, (2008), Increasing the Effectiveness and Efficiency of SOA Through Governance ،2008 SOA Governance Survey Report

[4] ITGI,(2007), Control Objectives for Information and related Technology (COBIT), Ver 4.1 
International Journal of Managing Information Technology (IJMIT) Vol.4, No.3, August 2012

[5] Siau. K, Rossi.M ,(1998), Evaluation of Information Modeling Methods - A Review, in Proc. 31 Annual Hawaii International Conference on System Science, pp. 314-322

[6] Peffers, K., Tuuanen, T., Rothenberger, M. A., Chatterjee, S.(2007). A Design Science Research Methodology for Information Systems Research, Journal of Management Information Systems, 24(3): 45-77.

[7] Hevner, AR., March, ST., Park, J., Ram, S.(2004). Design science in information systems research, MIS Quarterly 28(1):75-105

[8] Hojaji, F., \& Ayatollahzadeh Shirazi, M. R. (2010a). Developing a More Comprehensive and Expressive SOA Governance Framework, Proceedings 2010 2nd IEEE International Conference on Information Management and Engineering, China, 16-18 April, pp. 563-567

[9] Hojaji, F., Ayatollahzadeh Shirazi, M. R. (2010b). A Comprehensive SOA Governance Framework Based on COBIT. , 6th IEEE World Congress on Services (SERVICES 2010),USA,pp. 407-414

[10] Afshar M (2007) SOA Governance: Framework and Best Practices. Oracle. http://i.zdnet.com/whitepapers/oracle_soagovernancebestpractices.pdf. Accessed July 20, 2007

[11] Allen P.(2008). SOA Governance: Challenge or Opportunity?, CBDI Forum, http://www.cbdiforum.com/secure/interact/2008-e_opportunity_br.php

[12] Bieberstein N., Bose, S., Fiammante, M., Jones, K., Shah, R. (2006). Service-Oriented Architecture (SOA) Compass - Business Value, Planning, and Enterprise Roadmap, IBM developerWorks

[13] Brown W A, Moore G, Tegan W (2006) SOA Governance - IBM's Approach. IBM express

[14] Castaldini F (2008) SOA Governance and CentraSite Ensuring SOA success with effective, automated control throughout the lifecycle. Software AG. http://www.softwareag.com/be/images/SAG_SOAGov_CentraSite_WP_Apr08web\%5B1\%5D_tcm47-40610.pdf. Accessed Apr 10, 2010

[15] Webmethods.(2006). SOA governance: enabling sustainable success with SOA, http://www.cioindex.com/enterprise_architecture/ArticleId/1091/Enabling-Sustainable-Success-withSOA.aspx.

[16] Weill. P, Ross. J.W.(2004). IT Governance, Harvard Business School Press

[17] Office of Government Commerce .(2007). Official Introduction to ITIL Service Lifecycle, TSO

[18] Baer T. (2009), "SOA - ITIL Governance Synergy",www.ebizq.net

[19] Open Group.(2006). OSIMM: The Open Group Service Integration maturity Model

[20] Lin, C., Kavi, K.M., Sheldon, F.T., Daley, K.M., Abercrombie, R.K.(2008). A Methodology to Evaluate Agent Oriented Software Engineering Techniques, IEEE Proc. HICSS-40

[21] Schepers, T.G.J., Lacob , M.E., Van Eck ,P.A.T.(2008). A lifecycle aporoach to SOA Governace, ACM 978-1-59593-753-7

[22] Sturm, A ,Shehory. O.(2003). A Framework for Evaluating Agent-oriented Methodologies, AOIS, Springer LNCS 3030

[23] Hojaji, F., Ayatollahzadeh Shirazi, M. R. (2012),A Framework for Evaluating SOA Governance Frameworks, Journal of Theoretical and Applied Information Technology, Vol 40,June 2012 Inpress

[24] Shaw. M,(2002), What Makes Good Research in Software Engineering, International Journal of Software Tools for Technology Transfer,vol.4,no.1,pp.1-7

[25] Spencer, L., Ritchie J. Lewis, J. Dillon,L. (2003). Quality in Qualitative Evaluation: A framework for assessing research evidence, ISBN:07715 044658

[26] Ballinger C. (2004). Writing Up Rigour: Representing and Evaluating Good Scholarship in Qualitative Research, The British Journal of Occupational Therapy, 67(12): 540-546.

[27] Finlay L. (2006). 'Rigour', 'ethical integrity' or 'artistry'? Reflexively reviewing criteria for evaluating qualitative research

[28] Niemann. M, (2008), "Governance for Service-oriented Architectures : An Implementation Approach", I- ESA2008 